ПРАВА ИНТЕЛЛЕКТУАЛЬНОЙ СОБСТВЕННОСТИ

\title{
INTELLECTUAL PROPERTY RIGHTS
}

Научная статья

Original article

УДК $347.785,347.786$

DOI: https://doi.org/10.17323/tis.2021.13238

\section{ПОДКАСТЫ И ИНТЕЛЛЕКТУАЛЬНАЯ СОБСТВЕННОСТЬ PODCASTS AND INTELLECTUAL PROPERTY}

\section{Наталья Владимировна БУЗОВА}

Российский государственный университет правосудия, Москва, Россия, nbuzova@yandex.ru, https://orcid.org/0000-0003-2268-0345

Информация об авторе

Н.В. Бузова - ведущий научный сотрудник, кандидат юридических наук

Аннотация: Развитие технологий способствует появлению новых способов распространения информации и доведения ее до сведения представителей общественности. В результате могут создаваться объекты, которые обозначаются не использовавшимися ранее терминами. Создаваемые в цифровой среде объекты могут относиться к результатам интеллектуальной деятельности, заслуживающим правовой охраны. В статье исследуется возможность применения института интеллектуальной собственности (авторского права и смежных прав) к объектам, именуемым подкастами. Определяются правовые режимы, которые могут применяться к элементам, составляющим подкаст, и к подкасту в целом.

Ключевые слова: авторское право, аудиовизуальное произведение, вещание, интеллектуальная собственность, исключительное право, исполнение, передача, подкаст

Для цитирования: Бузова Н.В. Подкасты и интеллектуальная собственность // Труды по интеллектуальной собственности (Works on Intellectual Property).

2021. T. 38, № 3. C. $11-16$;

https://doi.org/10.17323/tis.2021.13238

\section{- Natalia V. BUZOVA}

- Russian State University of Justice, Moscow, Russia,

- nbuzova@yandex.ru,

- https://orcid.org/0000-0003-2268-0345

- Information about the author

- N.V. Busova - leading researcher,

- Candidate of Legal Sciences

- Abstract: The development of technology contributes

- to the emergence of new ways to distribute information and communicate it to the public. As a result, objects can be

- created that are called previously unused terms. Objects created in the digital environment may relate to the

- results of intellectual activity that deserve legal protection. The article examines the possibility of applying the institute

- of intellectual property (copyright and related rights) to objects called podcasts. It defines the legal regimes that

- can be applied to the elements that make up a podcast and to the podcast in general.

Keywords: copyright, audiovisual work, broadcasting,

- intellectual property, exclusive right, performance, broadcast, podcast

For citation: Buzova N.V. Podcasts and Intellectual Property // Trudi po Intellectualnoy Sobstvennosti

- (Works on Intellectual Property). 2021. Vol. 38 (3). P. $11-16$;

. https://doi.org/10.17323/tis.2021. 13238 
Амя того чтобы стать знаменитым в современных условиях, не обязательно создавать роман в стихах, как у А.С. Пушкина «Евгений Онегин», или романэпопею, как у $\Lambda . Н$. Толстого «Война и мир», быть С.В. Рахманиновым, П.И. Чайковским, К.П. Брюммовым, И.И. Шишкиным и т.А. Аюбой человек, написав небольшую заметку, сАелав фотографию мибо записав видеоролик, в настоящее время в соответствии с Аействующим законодательством в сфере интемлектуальной собственности будет явцяться автором, и в отношении него будут признаны интемектуальные права. Разместив такую заметку, видеоролик или фотографию в интернете, он может неожиАанно стать попумярным во всем мире или вслеАствие конкуренции так и остаться никому не известным, поскольку количество ежеАневно создаваемых и размещаемых в Сети произведений растет почти в геометрической прогрессии. В последние Аесятилетия человечество меняет свое отношение к творчеству и его результатам, существенные изменения произошии с появлением информационно-телекоммуникационных сетей. Характерный Аля современности количественный рост числа произведений одновременно приве к качественным изменениям: снижению творческого вклада авторов в созАание произведений и упрощению их содержания.

В век больших скоростей и мавинообразного увеличения объема информации человеку иногда не хватает времени на чтение научно-попумярной и публицистической митературы. Распространение информационно-телекоммуникационных сетей, в том числе интернета, предоставило возможность получения информации посреАством проскушивания сообщений на интересующие темы. В послеАние годы набирает попуяярность новый виА объектов, распространяемых или Аоводимых Ао всеобщего сведения через интернет; этот виА называют подкастами.

В настоящей статье рассматривается возможность правовой охраны подкастов в рамках института интемлектуальных прав и отмечаются наиболее приеммемые правовые режимы, которые применимы Аля таких объектов. В процессе провеАения исслеАования использовались метод сравнительного анализа, метоА системности, формально-Аогический метод и Аругие. Исследование основано на анализе законодательства
Российской Федерации в области авторского права и смежных прав, а также межАународных договоров в указанной сфере.

В ст. 1225 ГражАанского кодекса Российской Федерации (Аалее - ГК РФ) приведен ограниченный перечень результатов интелмектуальной деятельности, охраняемых в Российской Федерации в качестве интелмектуальной собственности. Но это не означает, что в отношении новых объектов, создаваемых в цифровой среде и используемых в ней, не могут признаваться интемлектуальные права. К новым «цифровым» объектам могут быть применены правовые режимы, используемые Аля охраны объектов интемлектуальной собственности, указанных в ст. 1225 ГК РФ. Аналогичная идея высказана, в частности, В.О. Камятиным в рамках Аискуссии «Новые объекты цифровой среАы и меАийного пространства vs классики интемлектуальной собственности»? .

Понятие «ПоАкаст» преАставмяет собой комбинацию английских слов «iPod» и «broadcast». Авторство понятия «подкастинг» приписывают журналисту Бену Хамерсли, который впервые употребил его в своей статье в 2004 г., хотя идея записи аудиофайлов в специальном формате и распространения их через интернет Аля проскушивания на МР3-пиеерах появимась еще 2000 г. и реализована Аейвом Винером.

Подкаст не относится к технологии, специально требующей iPod, и не передает информацию пользователям. Подкасты - это мультимеАийные файлы, которые загружаются пользователем по подписке 2 . Подкаст представмяет собой медиафайл (как правило, в MP3-формате), распространяемый через информационно-телекоммуникационную сеть по подписке, который пользователь может прослушать на своем компьютере или цифровом меАиапиеере ${ }^{3}$.

\footnotetext{
1 IP Академия (Москва, 18-20 сентября 2019 г.).

2 Information Communication Technologies for Enhanced Education and Learning: Advanced Application and Developments / ed. Tomei L.A. Information Science Reference. Hershey; New York. 2008. P. 250.

3 Gronstedt A. Basics of Podcasting: E-learning \& Training Technology //American Society for Training \& Development. 2007. P. 1.
} 
Ассоциированный чиен КафеАры ЮНЕСКО по авторскому праву, смежным, культурным и информационным правам НИУ ВШЭ В.А. Энтин относит к подкастам цифровую запись радио- или телепрограммы, скачиваемую из интернета, т.е. радио-, ТВ- и интернет-вещание 4 . Такой подход неслучаен. У пользователей может создаваться эффект трансляции, поскольку иногАа подкасты По ПоАПиске рассыцаются автоматически пользователям, может быть Ааже определена программа (время и/или периодичность) таких рассылок, они могут представцять собой серию файлов, объединенных общей темой.

Понятие «сообщение переАачи организаций вещания», которое используется в России Аля обозначения объекта смежных прав, в ГК РФ не опреАелено. В ст. 1225 ГК РФ и Аалее указано, что синонимом сообщения передачи организации вещания является «вещание». Российские специалисты, например В.О. Камятин, поясняют, что речь идет именно о процессе, осуществцяемом организацией вещания ${ }^{5}$, посреАством которого у слушателя или зрителя (преАставителя широкой общественности) появмяется возможность принимать теле- и раАиопередачи на свои устройства Аля просмотра и проскушивания.

Представляется, что подКастинг не относится к разновидности вещания, и это связано не с тем, что в Российской Федерации вещание, рассматриваемое как объект смежных прав, осуществцяется специализированными субъектами - организациями кабемьного и эфирного вещания. В периоА зарожАения поАкастинга оАними из активных созАателей поАКастов были организации вещании, например Би-би-си 6 . Они записывали свои радиопередачи (радиопрограммы) и размещали их в интернете на своих сайтах. Но в настоящее время с учетом развития технологий создавать подкасты может практически Аюбой желающий. Осуществление такой Аеятельности возможно как юридическими, так и физическими мицами. Аля нее не требуется получать специальную мицензию на осуществление вещания или иметь специальный статус.

В Российской Федерации информационно-телекоммуникационные сети не поименованы в ГК РФ как среда вещания передач организаций вещания. В этой связи некоторые исследователи ставят поА со-

\footnotetext{
4 Энтин В.Л. Интеллектуальная собственность в праве Европейского Союза. М.: Статут, 2018. 174 с.

5 Комментарий к части четвертой Гражданского кодекса Российской Федерации (постатейный) / Отв. ред. Е.А. Павлова. М.: ИЦЧП им. С.С. Алексеева, 2018. С. 346.

6 BBC (British Broadcasting Corporation) - Британская вещательная корпорация.
}

мнение охрану интернет-вещания в России ${ }^{7}$. Вместе с тем представляется, что разграничение подкастинга и вещания не следует связывать со средой распространения материала. Во всем мире, включая Россию, в последнее время развивается интернет-вещание. Просмотр и прослушивание переАач могут осуществцяться в режиме реального времени, который Аоступен на сайтах веАущих российских радиостанций и телеканалов (организаций вещания). И на практике исключительные права организаций вещания в интернете, в том числе в связи с потоковым вещанием, защищаются в судебном порядке ${ }^{8}$.

ПоАкастинг не явмяется процессом, трансляции подкастов не происходит. ПреАставмяется, что поАкастинг близок к радио и видео по требованию. В отмичие от «настоящего» интернет-вещания, которое преАставмяет собой потоковые трансляции в режиме реального времени, подкастинг ограничивается размещением мультимедийных файлов в интернете. Медиафайлы загружаются на сервер и могут АовоАиться Ао всеобщего сведения. Вероятностный характер АовеАения Ао всеобщего свеАения в российском понимании обусловлен тем, что поАкасты могут быть свободными Амя скачивания (воспроизведения) на устройства в кичных целях мюбым мицом, а могут распространяться только по поАписке ограниченному (заранее определенному) кругу миц.

В большинстве случаев информация в подкастах преАставлена в форме радио-ток-шоу'. Подкасты ближе по своей природе к объектам, именуемым в России радио- и телепередачами. Они создаются в стиле радио- и телепередач, хотя таковыми в соответствии с нормами российского законодательства не явцяются. В российском законодательстве отсутствует развернутое определение понятия «передача», в ст. 1329 ГК РФ указывается на совокупность звуков и (ими) изображений или их отображений. Такое пояснение не раскрывает сущности этого объекта. Пояснение ввеАено в большей степени с целью отАелить сообщения (вещание) как процесс, который относится к объектам смежных прав, от непосредственно радио- и темепередач, которые рассматриваются как содержание сообщений организаций вещания и могут охраняться, например, авторскими правами. Передачи организаций вещания имеют целевую направленность, которая выступает квалифицирующей характеристикой,

7 Матвеев А.Г. Природа и система смежных прав: Монография. Уфа: Аэтерна, 2020. С. 121.

8 См., например: судебные акты Московского городского суда. - URL: https://mos-gorsud.ru/mgs/defend

9 Bender W.N. Project-Based learning. Differentiating Instruction for the 21 st Century. Corwin. A Sage Company. 2012. P. 140 
позволяющей отмичать передачи от Аругих творческих и информационных объектов. Как уже было отмечено выше, в отличие от переАач, которые преАназначены Аля трансмяции широкой публике, подкасты распространяются по поАПиске Аибо Аоводятся Ао всеобщего свеАения в интернете.

Подкасты являются комплексным объектом, помимо речи ведущего (веАущих) они могут содержать звуковое сопровожАение, аннотацию, ключевые слова, изображения, комментарии и т.А. Но Аля отнесения Аанного объекта к сложному он Аолжен включать в себя несколько охраняемых результатов интелмектуальной деятельности (п. 1 ст. 1240 ГК РФ). Кроме того, результаты, включенные в сложный объект, Аолжны быть разнородными, но вместе с тем образовывать еАиное целое ${ }^{10}$. Рассмотрим некоторые элементы, составляющие содержание подкаста.

Текст, произносимый ведущим, можно рассматривать как митературное произведение. Но охраняется $\Lambda и$ такое произведение в качестве объекта авторского права?

С оАной стороны, текст подкаста имеет невысокую художественную направленность (не такую, какой обладают романы, стихи и прочие аналогичные произведения) и упрощенную структуру. Внешне такой текст, читаемый или декламируемый ведущим, может быть близок к сообщению о событиях и фактах, имеющих исключительно информационный характер, и в соответствии с поАП. 4 п. 6 ст. 1259 ГК РФ не явцяется объектом авторского права. НепосреАственно на информацию о фактах как таковую не распространяются положения об авторском праве. Положение российского законодательного акта соответствует общемировым подходам, заложенным п. 8 ст. 2 Бернской конвенции об охране китературных и художественных произведений (Берн, 9 сентября 1886 г.; Аамее Бернская конвенция).

С Аругой стороны, организаторы подкаста, которые одновременно могут быть авторами и ведущими, выбирают тему повествования. В основу текста поАкаста закладывается идея, которую следует донести Ао слушателя или зрителя, и в процессе повествования такая идея Аолжна развиваться. Несмотря на незначительное применение художественно-выразительных среАств при созАании текста и упрощенную структуру такого произведения, сохраняется творческая индивидуальность Аанного объекта. К. Мазуйе, разъ-

10 Заключение Исследовательского центра частного права по вопросам толкования и возможного применения отдельных положений части четвертой Гражданского кодекса Российской Федерации // Вестник гражданского права. 2007. № 3 С. 124. ясняя положения Бернской конвенции, отмечает, что и сообщения журналистов и репортеров, и их комментарии новостей явмяются «результатом достаточного интемлектуального усилия» Аля отнесения их к митературным и художественным произведениям ${ }^{11}$. Анамогичной позиции придерживается и М. Фичор, ссылаясь на отчет Основного комитета I Стокгольмской конференции 1967 г. по пересмотру Бернской конвенции $^{12}$.

В Российской Федерации, в целом, исходят из общей презумпции творческого характера произведений, которая может быть оспорена в судебном порядке. Следует также отметить более низкий творческий вкмаА, который характерен Аля многих сообщений в интернете, но и такие многочисленные произведения современных интернет-авторов охраняются авторским правом, на что обращают внимание специалисты ${ }^{13}$. Таким образом, текст подкаста, произносимый веАущим, относится к митературным произведениям, охраняемым авторским правом.

Непосреаственно речь ведущего может быть отнесена к исполнению, а ведущий может быть признан исполнителем. Статья 1313 ГК РФ содержит общее определение исполнителя, носящее описательный характер. В нем указано, что к артистам-исполнителям относится в том числе мицо, которое читает, Аекламирует или иным образом участвует в исполнении произведения китературы. В отличие от Закона Австрамии «Об авторском праве», в соответствии с которым не может рассматриваться в качестве исполнения чтение, повествование (изможение) или произнесение мюбого блока новостей или информации (подп. «b» п. 2 ст. $248 \mathrm{~A})^{14}$, российское законодательство не соАержит каких-либо ограничений или исключений в части характера исполнения, хотя и указывает виды произведений и иных объектов, которые могут быть исполнены. То есть в законодательстве прослеживается четкая зависимость правовой охраны исполнения

11 Международные конвенции об авторском праве. Комментарий под ред. Э.П. Гаврилова. М.: Прогресс, 1982. С. 43.

12 Руководство к договорам ВОИС в области авторского права и смежных прав. М. Фичор. Публикация ВОИС № 891 (R). Женева, 2003. С. 34.

13 Например, Е.А. Павлова, в докладе «Актуальные проблемы распоряжения исключительными правами» на круглом столе памяти проф. А.Л. Маковского «Интеллектуальные права в современном мире», в рамках международной практической конференции «Модернизация гражданского законодательства» $\{X V$ Ежегодные научные чтения, посвященные памяти проф. С.Н. Братуся, организуемые Институтом законодательства и сравнительного правоведения при Правительстве Российской Федерации (Москва, 21, 22 и 24 октября 2020 г.)\}. 14 Australia. Copyright Act 1968 (consolidated as of January 1, 2019). - URL: https://wipolex.wipo.int/en/text/501166 
и признания мица исполнителем от вида произведения и объекта, которое он исполняет. Аанный поАхоА преАставляется приемлемым и Аля подкастов. Если повествование ведущего относится к митературному произведению, то само повествование будет признано охраняемым исполнением.

Создаются разАичные виды подкастов; наибомее распространенными явцяются аудиоподкасты и видеоподкасты. Изначально преоблаАали аудиопоАкасты, в которых звуковое повествование ведущего записывалось, монтировалось, обрабатывалось и так Аалее, и тем самым создавацась фонограмма. В качестве разновиАности подкастов иногАа рассматривают аудиокниги. В России на основе правоприменительной практики ${ }^{15}$ в отношении аудиокниг применяется правовой режим, установленный Аля фонограмм.

В Аальнейшем получили развитие и видеопоАкасты. В некоторых странах, например в Армении, Украине, Франции, Швейцарии, видеопрограммы охраняются как самостоятельные результаты интелмектуальной Аеятельности. В соответствии с Аействующим российским законодательством самостоятельная правовая охрана в качестве результата интемлектуальной деятельности видеозаписям (видеограммам) не предоставмяется ${ }^{16}$.

В то же время видеоподкасты могут быть отнесены к сложным объектам. Вместе с тем в ГК РФ перечень сложных объектов ограничен примерами, приведенными в ст. 1240, к которым отнесены аудиовизуальные произведения, театрально-зрелищные преАставления, мультимеАийные продукты и базы Аанных.

Можно преАположить, что подкасты ближе к мультимедийным продуктам. Но специалисты связывают мультимедийность со ссылкой на Постановление Правительства Российской Федерации от 17 мая 1996 г. № $614^{17}$, в котором упоминакась программа интерактивного типа «мультимедиа» с наличием интерактивности $^{18}$. Так, Е.С. Котенко, опредемяя мультимедийный продукт как «выраженный в эмектронной

15 См., например, решение Московского городского суда от 1 октября 2019 г. по делу № 3-453/2019.

16 Следует отметить, что в соответствии с Основами гражданского законодательства Союза ССР и республик 1991 г., утвержденными Верховным Советом СССР 31 мая 1991 г., №2211-І видеозаписи охранялись в качестве объектов смежных прав (ст. 141).

17 Постановлением Правительства Российской Федерации от 16 февраля 2019 г. № 155 указанное постановление было признано утратившим силу.

18 Комментарий к части четвертой Гражданского кодекса Российской Федерации (постатейный) / отв. ред. Е.А. Павлова. М.: ИЦЧП им. С.С. Алексеева, 2018. С. 108. (цифровой) форме объект авторских прав, который вкцючает в себя несколько охраняемых результатов интемлектуальной Аеятельности...», отмечает его взаимодействие с пользователем с помощью компьютерных устройств ${ }^{19}$. Кроме того, к квалифицирующим признакам мультимедийных продуктов помимо интерактивности относят сложность и виртуальность ${ }^{20}$, а также техническую применимость и функциональность $^{21}$. ПослеАние Ава признака преАставляются Аискуссионными; возможно, автор, преАлагающий такие признаки, хотец тем самым показать связь мультимеАийного проАукта с программой Аля ЭВМ.

Полагаю, что интерактивность обеспечивается наличием обратной связи, которая образуется при обращении к мультимеАийному продукту межАу ним и пользователем, что характерно, например, Аля компьютерных игр ${ }^{22}$. В подкастах отсутствует интерактивность, они не предполагают активных действий преАставителя общественности. Совершаемые пользоватемями Аействия по включению, выключению, приостановке и скачиванию материалов не вцияют на содержание повествования в подкасте.

Представмяется, что в отношении видеоподкастов может быть распространен правовой режим, применяемый к аудиовизуальным произведениям. Их характеристики не выходят за рамки определения «аудиовизуального произведения», приведенного в п. 1 ст. 1263 ГК РФ. При этом такие объекты должны удовлетворять требованиям, указанным в Постановлении Суда по интемлектуальным правам от 30.01.2017 № С01-1029/2016 по Аеку № А40-14248/2016, а именно: 1) состоять из зафиксированной серии связанных межАу собой изображений; 2) быть как с сопровожАением, так и без сопровожАения звуком; 3) восприниматься с помощью соответствующих технических устройств зрительно, а при наличии звукового сопровождения - и на слух; 4) восприниматься как сложный объект; 5) быть созАанными творческим трудом авторов $^{23}$.

19 Котенко Е.С. Мультимедийный продукт как объект авторских прав. Автореферат дисс. ... канд. юр. наук: 12.00.03. M. 2012. C. 9.

20 Котенко Е.С. Указ.соч. С. 9

21 Усенко А.С. Правовой режим мультимедийных продуктов // Научный журнал «Эпомен». 2019. № 24, С. 299.

22 Котенко Е.С. Авторские права на мультимедийный продукт: Монография. М.: Проспект, 2013. 123 с.

23 Постановление Суда по интеллектуальным правам от 30.01.2017 № C01 - 1029/2016 по делу A40-14248/ 2016 - URL: https://kad.arbitr.ru/Document/Pdf/ca03b6253e33-460c-86d 1-63a5a0c876da/48508757-fee 1-4537aec0-309fef85c81d/A40-14248-2016_20170130_Reshenija_i_ postanovlenija.pdf?isAddStamp=True 
Следовательно, в случае удовлетворения подкастов приведенным выше требованиям к ним могут быть применены положения ст. 1240 ГК РФ, посвященные сложным объектам.

Таким образом, несмотря на то что некоторые создаваемые в цифровой среде объекты не поименованы в качестве самостоятельных результатов интелмектуальной деятельности в законодательных актах (в частности, в ст. 1225 ГК РФ), на такие объекты могут быть распространены правовые режимы, применимые в отношении результатов, поименованных в законодательстве. И, хотя художественная ценность подкастов небесспорна, в отношении этих объектов признаются интемектуальные права. Использование подкастов, в частности их запись и распространение экземпляров, их доведение Ао всеобщего сведения, за искиючением случаев, обозначенных в ГК РФ, требует согласия правообладатемя. В зависимости от вида поАкаста речь может иАти об изготовителе фонограммы (Аля аудиоподкастов) или о группе правообладателей, вкцючая изготовителя фонограммы, если последнему не были переданы исключительные права на отдельные элементы подкастов (права на митературное произведение, на исполнение и т.А.).

В отношении видеопоАКастов помимо группы правообладателей может быть определено мицо, организовавшее создание сложного объекта, которое приобрело права на результаты, входящие в состав сложного объекта, на основании соответствующих Аоговоров о распоряжении искмючительным правом.

\section{спИсок Источников}

Комментарий к части четвертой Гражданского кодекса Российской Федерации (постатейный) / Отв. ред. Е.А. Павлова. М.: ИЦЧП им. С.С. Алексеева, 2018. $928 \mathrm{c}$.

Котенко Е.С. Мультимедийный продукт как объект авторских прав. Автореферат дисс. ... канд. юр. наук: 12.00.03. М. 2012. 26 с.

Котенко Е.С. Авторские права на мультимедийный продукт: Монография. М.: Проспект, 2013. 123 с.

Матвеев А.Г. Природа и система смежных прав: Монография. Уфа: Аэтерна, 2020. 176 с.

Международные конвенции об авторском праве: Комментарий под ред. Э.П. Гаврилова. М.: Прогресс, 1982. 423 c.

Усенко А.С. Правовой режим мультимедийных продуктов // Научный журнал «Эпомен» 2019. № 24, С. 288-302.

Руководство к договорам ВОИС в области авторского права и смежных прав. М. Фичор. Публикация BОИС № 891 (R). Женева, 2003. 322 с.
Энтин В.Л. Интеллектуальная собственность в праве Европейского Союза. М.: Статут, 2018. 174 с.

Bender W.N. Project-Based learning. Differentiating Instruction for the 21 st Century. Corwin. A Sage

Company, 2012.

Gronstedt A. Basics of Podcasting: E-learning \& Training Technology. American Society for Training \& Development, 2007.

Information Communication Technologies for Enhanced Education and Learning: Advanced Application and Developments / ed. L.A. Tomei Information Science Reference. Hershey. New York, 2008.

\section{REFERENCES}

Bender W.N. Proyektnoye obucheniye. Differentsial'naya instruktsiya dlya 21 veka. Korvin, kompaniya Sage, 2012.

Entin V.L. Intellektual'naya sobstvennost' $v$ prave Yevropeyskogo Soyuza. M.: Statut, 2018. 174 p.

Gronstedt A. Basics of Podcasting: E-learning \& Training Technology. American Society for Training \& Development, 2007.

Information Communication Technologies for Enhanced Education and Learning: Advanced Application and Developments / Information Science Reference / ed. L.A. Tomei. Hershey; N.Y., 2008.

Kommentariy k chasti chetvertoy Grazhdanskogo kodeksa Rossiyskoy Federatsii (postateynyy) / otv. red. Ye.A. Pavlova. M.: ITSCHP im. S.S. Alekseyeva, 2018. $928 \mathrm{p}$.

Kotenko E.S. Avtorskiye prava na mul'timediynyy produkt: Monografiya. M.: Prospekt, 2013. 123 p.

Kotenko E.S. Mul'timediynyy produkt kak ob»yekt avtorskikh prav: avtoreferat diss. ... Kand. yur. nauk: 12.00.03. M., 2012. 26 p.

Matveyev A.G. Priroda i sistema dopolnitel'nykh prav: Monografiya. Ufa: Aeterna, 2020. 176 p.

Mezhdunarodnyye konventsii ob avtorskom prave: Kommentariy / pod red. E.P. Gavrilova. M.: Progress, 1982. 423 p.

Rukovodstvo k dogovoram VOIS v oblasti avtorskogo prava i smezhnykh prav / M. Fichor. Publikatsiya VOIS № 891 (R). Zheneva, 2003. 322 p.

Usenko A.S. Pravovoy rezhim mul'timediynykh produktov // Epomen: Nauchnyy zhurnal. 2019. № 24. P. 288-302. 